\title{
SISTEM INFORMASI DAPUR CERDAS UNTUK PEMBERITAHUAN DAN PENANGANAN TERHADAP KEBOCORAN GAS LPG BERBASIS MICROCONTROLER
}

\author{
Yul Hendra \\ Dosen Tetap Sistem Informasi, Universitas Banten Jaya \\ E-mail: yulhendra@unbaja.ac.id
}

\begin{abstract}
Liquid Petroleum Gas or well-known as LPG Gas is now a staple for every household in Indonesia, we often hear the explosion due to leakage from LPG gas cylinders in the room. Not a few casualties are falling as a result of LPG gas leak in this room. LPG gas that leaks in a closed room can be dangerous because the leaking gas cannot get out of the room, triggered either by matches, gas compost, gas is struck which causes a fire and even a great explosion. This is the background of this research, the author wants to make a prototype device that can prevent the occurrence of explosions or gas fires in the kitchen or a room. The method used in this study is a trial method, assembling microcontroller tools to enter program logic into it that can know that a gas leak has occurred. Not only that, after the device can detect that there has been a LPG gas leak in a room, then the device can also function as an anticipation of an explosion or fire, by automatically opening the kitchen or room window, by opening the room / kitchen window, then the gas will automatically exit the room and the fire and explosion will not occur. When a device detects a gas leak in the kitchen, the alarm will automatically sound as well as a tool to open the door as an automatic handling to avoid fire or explosion. So a series of processes and logic from this tool if applied in a kitchen or room will be able to become a system that works automatically in the detection, notifying, and anticipating the occurrence of fire or explosion due to LPG gas leak.
\end{abstract}

Keywords: Leakage, LPG Gas, Tool

\section{PENDAHULUAN}

Semakin banyaknya masyarakat yang menggunakan gas LPG untuk menggantikan kebiasaan yang lama yaitu menggunakan minyak tanah sehingga resiko Terjadinya kebocoran gas LPG yang tidak terduga, seringkali menyebabkan ledakan yang mengakibatkan kebakaran rumah, hal itu terjadi karena keteledoran kita dalam menggunakan gas elpiji tersebut baik itu dari segi pemasangan ataupun dari hal yang tak terduga, oleh sebab itu peniliti memilih ini mengingat kebakaran terjadi karena kebocoran gas LPG, hal itu disebabkan karena manusia mempunyai sifat lupa maka kejadian yang tidak diinginkan 
seperti kebakaran yang diakibatkan oleh kebocoran gas LPG, berita kebakaranpun sering terdengar akibat tabung gas LPG meledak, penyebab meledaknya tabung gas ini karena kebocoran pada selang tabung atau pada regulatornya yang tidak terpasang dengan baik, pada saat terjadi kebocoran akan tercium gas yang menyengat, gas inilah yang nantinya akan meledak apabila ada percikan api atau adanya nyala rokok,maka dari itu peniliti membuat sebuah solusi untuk mengatasi masalah tersebut karena pada intinya ledakan dapat dihindarkan apabila adanya pencegahan dini, saat gas keluar atau pada saat kebocoran gas terjadi. Seiring dengan perkembangan teknologi maka dikembangkanlah sebuah sistem keamanan dengan cara memberikan peringatan sebuah tanda jika ada tercium bau gas disekitar rumah.

Adanya ledakan tabung gas LPG yang menyebabkan kebakaran itu terjadi karena kebocoran pada selang gas atau pemasangan regulator yang tidak benar, maka dari itu pemecahan masalah tersebut ialah dibuatkan suatu alat yang mampu mendeteksi kebocoran gas elpiji tersebut, oleh sebab itu penilitti disini mencoba membuat alat dengan sensor gas yaitu sensor mq2 yang nantinya akan mendeteksi kebocoran gas, lalu alarm pun bebunyi untuk alarm kita menggunakan buzzer, kemudian mini servo motor yang nantinya akan dipasang pada jendela fungsinya ketika terjadi kebocoran gas maka jendela tersebut akan membuka sendiri, jadi ada dua output yang akan dihasilkan :

1. Alarm berbunyi dengan alat buzzer.

2. Jendela akan membuka sendiri dengan alat mini servo motor.

Dari masalah yang sudah dibahas di bagian sebelumnya maka disini peniliti mempunyai tujuan dari teknologi yang diciptakan yaitu pencegahan akan terjadinya kebakaran yang disebabkan karena kebocoran gas elpiji, karena dengan teknologi tersebut masyarakat dapat langsung mengambil keputusan karena sudah mengetahui apabila terjadi kebocoran suatu gas LPG, teknologi yang dicitakan sudah memberikan notofikasi tanda bahaya, kemudian jendela darurat akan terbuka sendiri agar gas LPG yang keluar tidak menggumpal atau terkurung kedalam ruangan sehingga sedikit meminimalisir terjadinya ledakan atau terkena percikan api dan itu akan membantu masyarakat yang sudah menggunakan gas LPG dalam kesehariannya. 
LPG atau liquefied petroleum gas merupakan campuran dari berbagai hydrocarbon, sebagai hasil penyulingan minyak mentah berbentuk gas, dengan menambah tekanan atau menurunkan suhunya membuat menjadi cairan. Inilah yang kita kenal dengan bahan bakar gas cair, terutama digunakan oleh para ibu rumah tangga dan restoran sebagai pengganti bahan bakar minyak yang kian menipis persediaannya, secara garis besar, fungsi LPG yaitu:

1. Sebagai bahan bahan rumah tangga meliputi kompor, pemanas air dan lampu penerangan.

2. Sebagai bahan bakar industry, meliputi industry makanan, kertas tekstil, percetakan, cat, keramik, gelas, industry logam, dan sebagainya.

3. Berguna pula sebagai bahan penekan atau zat penyemprotan seperti pada obat nyamuk spray, Cat spray(pilox) dan deodorant

4. Sebagai bahan baku. Sedangkan bahan bakar gas elpiji mempunyai ciri khas yaitu :

1) Sensitive terhadap api.

2) Mudah terbakar.

3) Mempunyai daya pemanas yang tinggi.

4) Tidak menyebabkan pengkaratan pada besi dan tabung kemasan.

Komponen utama dalam alat pendeteksi gas LPG adalah sensor LPG itu sendiri, sensor ini berbasis mq2 yang peka terhadap gas LPG. Kemudina microcontroller arduino uno merupakan komponen utama pengendali alat secara keseluruhan dan suatu sistem komputer kecil pada suatu chip, sebenarnya semua jenis microcontroller dapat digunakan untuk membuat alat pendeteksi gas LPG ini, asalkan kita mampu memprogramnya, adapun dipilihnya jenis board microcontroller ini adalah kemudahan dalam memprogramnya, kemudian buzzer adalah alat yang dapat mengeluarkan suara yang nyaring bila dalam kondisi aktif, umumnya bazzer digunakan untuk memberikan signal untk menunjukkan kondisi tertentu, kemudian mini servo motor yaitu suatu alat yang digunakan sebagai penggerak yang dalam hal ini digunakan untuk menggerakkan jendela secara otomatis. Jadi dari deskripsi teoritik diatas peniliti berharap mampu menciptakan suatu alat dengan suatu komponen yang sudah disebutkan diatas yang mampu 
mendeteksi suatu kebocoran gas sehingga nantinya dapat membantu masyarakat pada umumnya, dalam hal pencegahan kebakaran yang disebabkan oleh kebocoran gas LPG.

\section{METODE PENELITIAN}

\section{1) Rancangan Perangkat Keras}

Karena sering terdapat kebocoran gas elpiji ini, maka sangat diperlukan untuk memasang alat ini pada tempat - tempat tetentu yang menggunakan gas LPG, cara kerja alat ini dapat dijelaskan secara sederhana sebagai berikut yaitu sebuah sensor gas jenis mq2 akan mendeteksi apakah terjadi kebocoran gas LPG atau tidak, bila tidak terjadi kebocoran, maka alat tidak akan menampilkan suatu tindakan tertentu, namun apabila terjadi kebocoran gas LPG, maka sensor gas yang dipasang akan mendeteksi adanya kebocoran gas LPG tersebut dan kemudian alarm menyala dan kemudian jendela akan terbuka sendiri karena sudah di atur dengan dipasang alat penggerak yaitu mini servo motor, komponen - komponen yang diperlukan untuk membuat alat pendeteksi kebocoran gas ini yaitu:

1. Arduino uno $r 3$.

2. Sensor mq2.

3. Buzzer.

4. Mini servo motor.

\section{2) Rancangan Perangkat Lunak}

Suatu alat yang berbasis mikrokontroller tidak akan dapat bekerja tanpa bagian software (perangkat lunak), karena mikrokontroler sendiri termasuk komponen yang diprogram agar dapat bekerja, maka kita harus terlebih dahulu memprogram atau mengisi mikrokontroller tersebut, arduino ini dikembangkan oleh para ahli di italia, arduino ini merupakan proyek open source, IDE (integrated development environment) yang dipakai juga dapat di download secara gratis di website arduino, untuk memprogram arduino ini tidak diperlukan alat programmer yang mahal, yang diperlukan hanya sambungan USB dari komputer ke arduino saja, kabel USB ini selain untuk 
menyalurkan data juga dapat memberikan daya listrik 5 volt seperti yang diperlukan arduino untuk beropersai.

\section{3) Sasaran Penelitian}

Penelitian ini ditujukan untuk masyarakat luas yang menggunakan tabung gas LPG sebagai alat keperluan untuk memasak.

\section{4) Teknik Pengambilan Data}

Adapun data yang digunakan selama penelitian yaitu peniliti menggunakan korek gas sebagai sempel penilitian untuk mengetehui alat yang dirancang bekerja atau tidak.

\section{HASIL DAN PEMBAHASAN}

Dengan semakin banyaknya masyarakat yang menggunakan gas LPG maka kemungkinan akan terjadinya kebocoran gas bisa saja terjadi, maka dari itu di sini peneliti sangat tertarik dalam bereksperimen untuk meneliti-nya. Karena peneliti memliki tujuan yaitu upaya pencegahan kebakaran yang diakibatkan oleh kebocoran gas elpiji baik itu dari selang maupun regulatornya, peneliti disini merancang sebuah alat yang mampu mendeteksi sebuah kebocoran gas, yang nantinya alat ini mampu memberikan suatu tanda apabila terdapat kebocoran gas.

Adapun cara kerjanya yaitu dengan sensor mq2 yang sudah dipasang maka sensor tersebut yang akan mendeteksi suatu gas kemudian setelah dideteksi maka selanjutnya akan ada alarm yang menyala dan jendela yang sudah di atur sebagai pintu darurat akan membuka sendiri ketika kebocoran gas itu terjadi, jadi intinya ialah dengan input satu yaitu gas dengan sensor gas mq2 terdapat dua output yaitu bunyi alarm dan jendela akan membuka sendiri.

Peniliti disini melakukan percobaan dengan membuat miniatur dapur yang sudah dipasang alat pendeteksi gas adapun gas yang digunakan yaitu peneliti menggunakan sampel korek gas, dengan bantuan teknologi yang dirancang maka akan membantu masyarakat walaupun sedang berada jauh dari rumahnya karena ketika terjadi kebocoran gas jendela yang sudah diset akan membuka sendiri agar gas keluar bebas tidak menggumpal di dalam ruangan yang dapat menyebabkan 
kebakaran ketika ada percikan api, dengan bantuan memasang alat servo motor pada jendela yang nanti jika ada kebocoran gas maka jendela itu akan membuka secara otomatis, setidaknya sedikit meminimalisir dan langkah awal untuk mengatasi kejadian kebakaran akibat ledakan gas yang disebabkan selang gas bocor atau pemasangan regulator yang tidak benar.

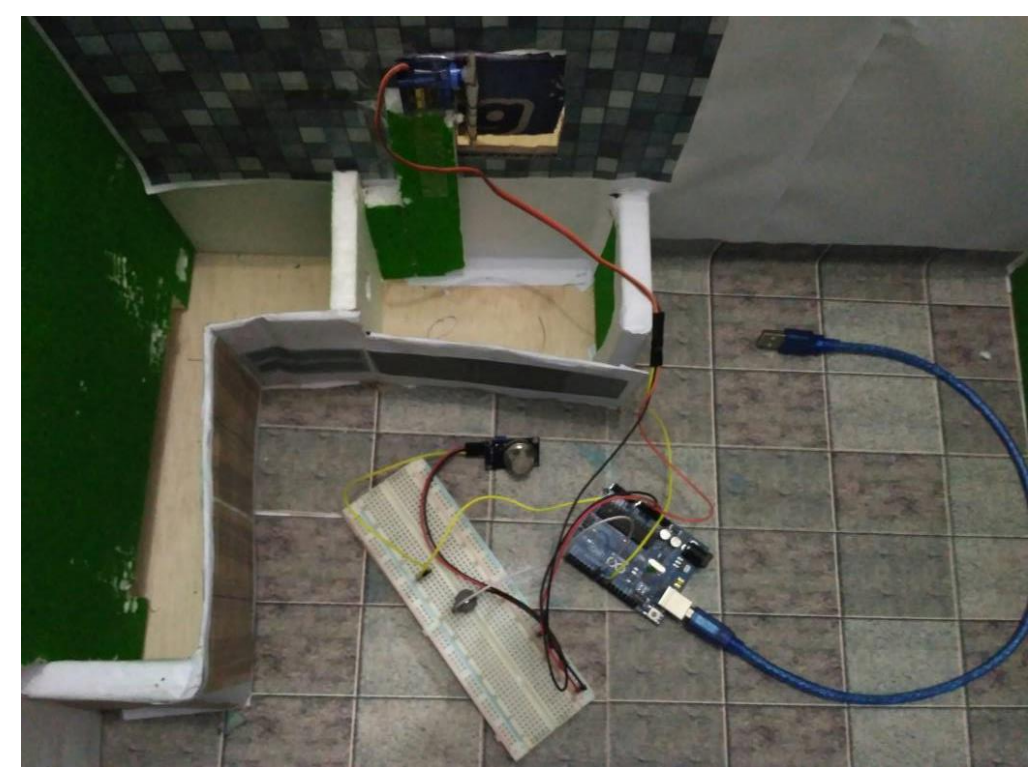

Gambar 1. Rancangan Alat

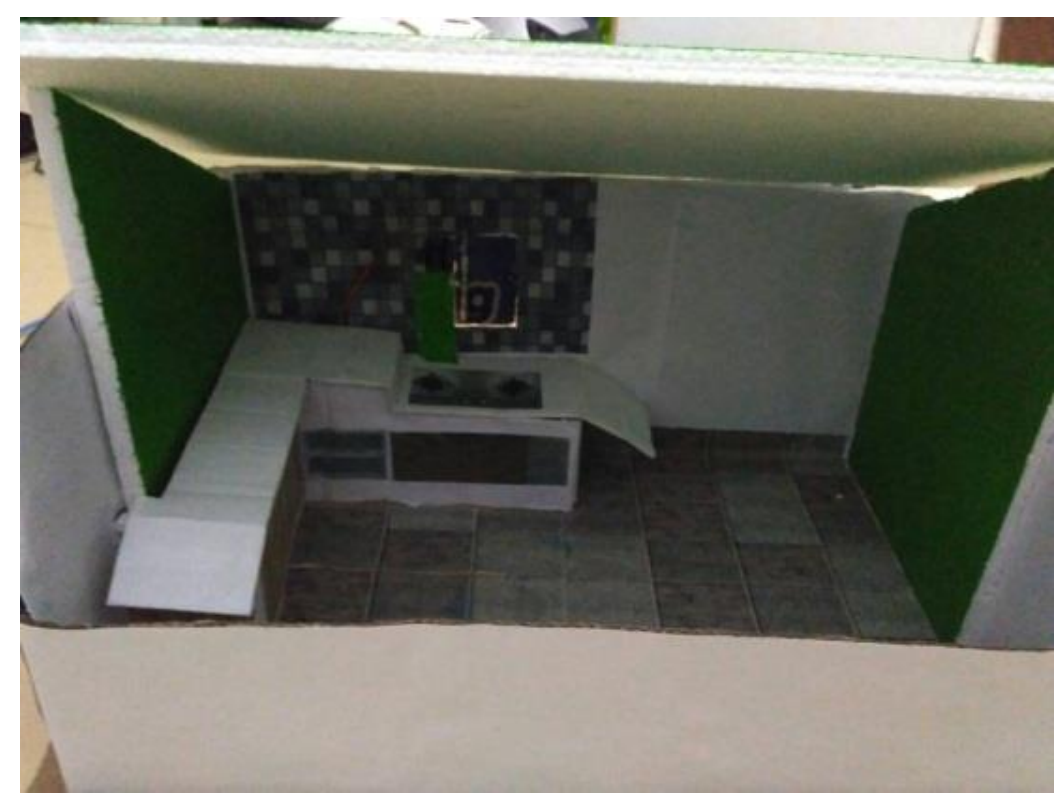

Gambar 2. Prototype Dapur Bagian Depan 


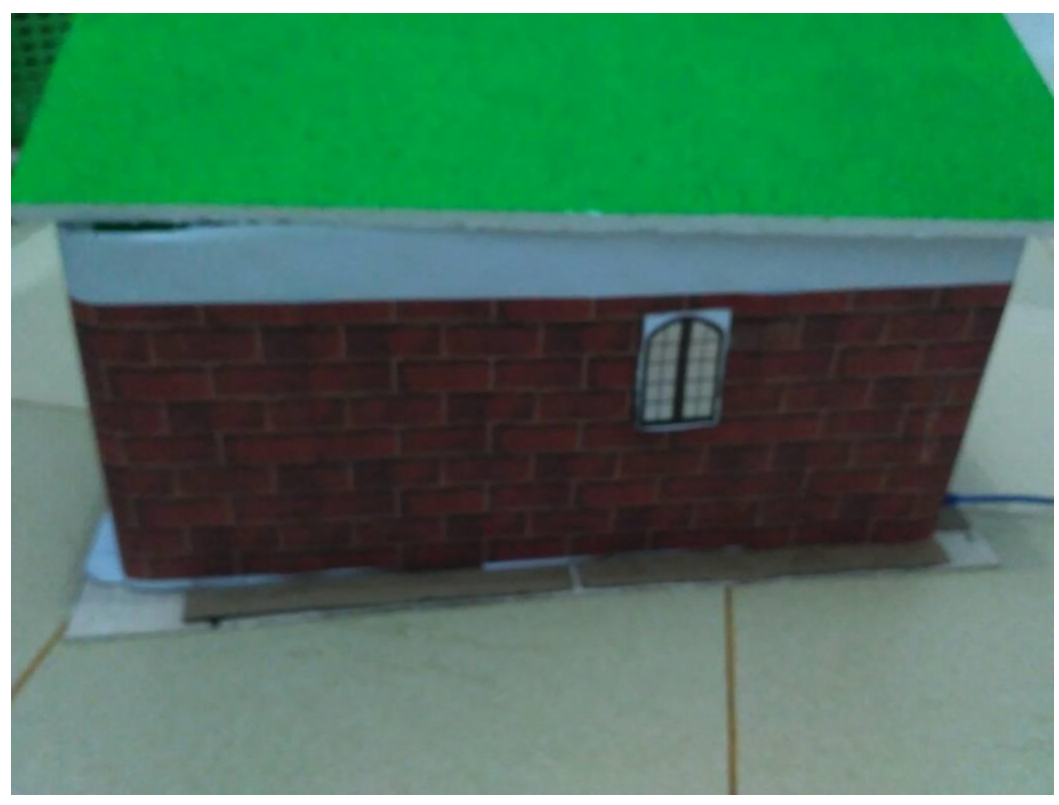

Gambar 3 Prototype Dapur Bagian Belakang

\section{KESIMPULAN}

Dengan menggunakan board mikrokontroller arduino uno ditambah dengan sensor gas mq2 dan dengan menggunakan sketch (program) tertentu, maka kita bisa membuat alat pendeteksi kebocoran gas LPG, alat ini tentunya sangat berguna untuk masyarakat atau siapapun yang menggunakan gas LPG, dikarenakan gas elpiji ini sangat sensitif apabila terkena percikan api makanya untuk mengatasi kebocoran gas elpiji dan nantinya akan menyebabkan ledakan maka dengan bantuan alat ini sedikit akan membantu dan meminimalisir akan adanya ledakan yang diakibatkan dengan kebocoran gas.

\section{Saran}

Alat ini ini berguna untuk mendeteksi adanya kebocoran gas elpiji, namun tidak hanya itu saja alat ini bisa dikembangkan lagi, misalnya penambahan modul GSM seingga jika terjadi kebakaran ada notifikasi pada handphone. 
Jurnal Sistem Informasi dan Informatika (SIMIKA)

Vol.1 No.1 tahun 2018

\section{DAFTAR PUSTAKA}

Ibnu malik moh. 2003. Belajar mikrokontroller AT89S8252. PT Gava Media.

Kompas.(2010). Pertamina hanya edarkan tabung ber-SNI. Juni.2, 2010.

Wadrianto, glori k. (2010).Kemelut tabung elpiji. Juni 25, 2010.

http://megapolitan.kompas.com/read/2010/06/25/10111552/Kemelut.Tabung. Elpiji

Djumena, erlangga.(2010). Konversi minyak ke gas selesai 2011. Agustus 16, 2010.

http://bisniskeuangan.kompas.com/read/2010/08/16/07312887/Konversi. Minyak. ke.Gas.Sele

Budioko, totok. 2005. Pemrograman bahasa C dengan SDCC pada mikrokontroller 89X51. PT Gava Media. 